This item was submitted to Loughborough's Research Repository by the author.

Items in Figshare are protected by copyright, with all rights reserved, unless otherwise indicated.

\title{
Improved utility and application of probabilistic methods for reliable mechanical design
}

PLEASE CITE THE PUBLISHED VERSION

http://dx.doi.org/10.1243/1748006XJRR244

PUBLISHER

Sage / Institution of Mechanical Engineers

VERSION

VoR (Version of Record)

LICENCE

CC BY-NC-ND 4.0

REPOSITORY RECORD

Goh, Yee M., Chris McMahon, and J.D. Booker. 2019. "Improved Utility and Application of Probabilistic Methods for Reliable Mechanical Design”. figshare. https://hdl.handle.net/2134/8010. 
This item was submitted to Loughborough's Institutional Repository (https://dspace.lboro.ac.uk/) by the author and is made available under the following Creative Commons Licence conditions.

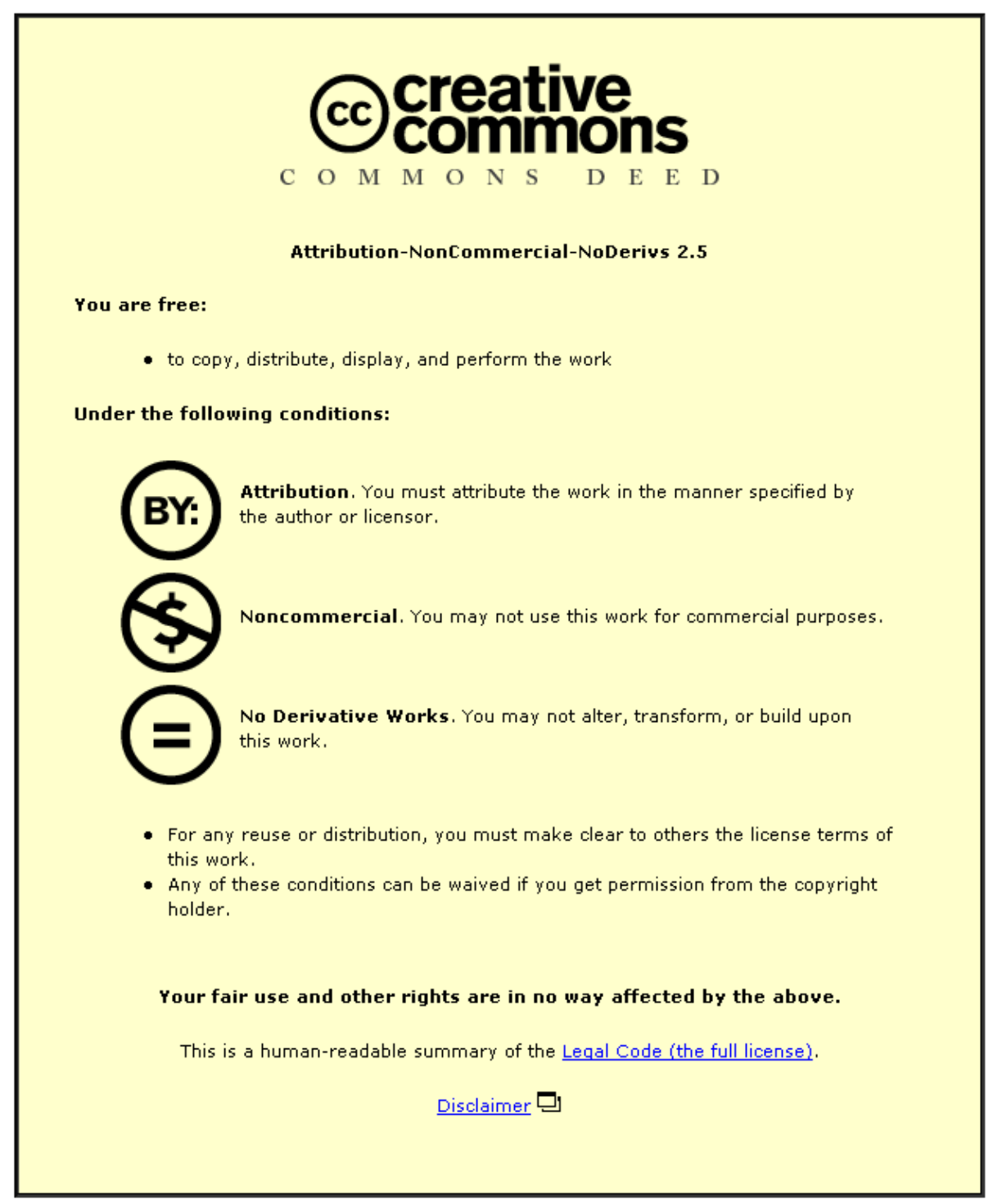

For the full text of this licence, please go to: http://creativecommons.org/licenses/by-nc-nd/2.5/ 


\title{
Improved utility and application of probabilistic methods for reliable mechanical design
}

\author{
Y M Goh ${ }^{1 *}$, C A McMahon', and J D Booker² \\ ${ }^{1}$ Department of Mechanical Engineering, University of Bath, Bath, UK \\ ${ }^{2}$ Department of Mechanical Engineering, University of Bristol, Bristol, UK
}

The manuscript was received on 5 February 2009 and was accepted after revision for publication on 18 May 2009.

DOI: $10.1243 / 1748006 X J R R 244$

\begin{abstract}
In a modern product development process such as in the automotive and aerospace sectors, extensive analytical and simulation approaches often are used to assess the ability of a design in fulfilling its requirements. Consideration of uncertainty in such situations is critical in ensuring a reliable design is produced. Probabilistic methods facilitate an improved understanding of design performance through characterization of uncertainty in the design parameters. The probabilistic methods developed over the past several decades have a range of capabilities and modes of application, for example, to predict reliability, for optimization, and to perform sensitivity studies, but have yet to be taken up routinely by industry due to a number of reasons. In this paper, issues that have typically inhibited their use or prevented a successful outcome are addressed through a systematic framework for improved utility and successful application of probabilistic designing for mechanical reliability.
\end{abstract}

Keywords: mechanical design, reliability, probabilistic methods, physics of failure, implementation

\section{INTRODUCTION}

A number of methods can be used to manage uncertainty in attaining high quality, reliable and cost-effective design during product development. These methods allow designers to better understand the impact of their decisions on the technical and economic performance of the design. Methods such as failure mode and effects analysis (FMEA) and fault tree analysis help designers to systematically consider and prioritize design efforts to satisfy the functionality and safety of the product in use. Statistical methods such as robust design and six sigma methodologies are also employed to evaluate the effects of uncertainty on product quality. Design for reliability (DFR) is a systematic approach to the design process that is sharply focused on probability of failure and firmly based on the physics of failure [1]. This is a branch of reliability engineering that is concerned

*Corresponding author: Innovative Design and Manufacturing Research Centre (IMRC), Department of Mechanical Engineering, University of Bath, Bath BA2 7AY, UK.

email:y.m.goh@bath.ac.uk mostly with the understanding of the physical processes of stress, strength, and failure at a detailed component level so that the material or component can be redesigned to reduce the probability of failure (POF). This is contrasted to system reliability and reliability engineering practices that are based on failure rates in service [2]. In a modern product development such as automotive and aerospace design, analytical and simulation approaches based on physics-of-failure modelling are used to assess the ability of a design in fulfilling its requirements. A complete probabilistic design requires thorough modelling of uncertainty in all critical design parameters to estimate the POF or statistical distribution of a desired performance function. As virtually all mechanical design variables such as dimensions, material properties, and service loads exhibit some statistical variability that influencs the adequacy of the design, the probabilistic methods are arguably the most realistic. Probabilistic-based approaches such as the first-order reliability method (FORM) and Monte Carlo simulation (MCS) provide suitable means for DFR to provide a quantitative estimation 
of the POF of the failure modes identified through FMEA.

The theoretical developments governing probabilistic design (PD) have been proposed for more than 40 years. Many methods have since been developed $[3,4]$. In PD, the same models as deterministic design are used, but variability in the design parameters is accounted for by describing these as random variables, determined from ideally testing statistically large sample sizes of the characteristics and properties of interest at the conditions expected in service for the designed product. Computational and statistical methods are then used to investigate the combination and interaction of these design parameters in the performance function or failure models. Conversely, deterministic design typically uses large factors of safety to account for variability in design parameters resulting in a loss of probability information. Primarily, probabilistic methods have been used to predict POF in static solid mechanics problems and fatigue problems associated with mechanical design analyses [5]. PD applications have also been found in designs where weight minimization is crucial, or when the design cannot be tested to failure such as those in aerospace [6, 7], nuclear [8], and marine industries [9]. In these situations, decision-making is based on thorough descriptions of the problem and uncertainties, and evaluating the performance of the product against reliability targets. Other emerging areas of application in research and development are in computational fluid dynamics (CFD) [10], finite element analysis (FEA) [11], or multi-body system (MBS) analysis [12].

Depending on the design objective, the mode of application of probabilistic methods may be one or a combination of those described in Table 1.

Figure 1 illustrates an important application mode of probabilistic methods, that of the prediction of a POF for a mechanical component. The design parameters for the geometry $(x, y, z)$ and the load, $F$ are characterized as a probability density function (PDF) to derive the loading stress distribution. The interference (shaded area) between the stress and material strength distributions represents the POF. The approach is commonly termed stress-strength interference analysis. The lack of control or understanding

Table 1 Modes of application and objectives of probabilistic design

\begin{tabular}{|c|c|}
\hline $\begin{array}{l}\text { Mode of } \\
\text { application }\end{array}$ & Objective \\
\hline $\begin{array}{l}\text { Sensitivity } \\
\text { analysis }\end{array}$ & $\begin{array}{l}\text { To determine the percentage contribution of } \\
\text { each design parameter to the variation in } \\
\text { performance parameters }\end{array}$ \\
\hline $\begin{array}{l}\text { Performance } \\
\text { modelling }\end{array}$ & $\begin{array}{l}\text { To determine the performance parameters from } \\
\text { the mapping of a set of design parameters }\end{array}$ \\
\hline $\begin{array}{l}\text { Reliability } \\
\text { analysis }\end{array}$ & $\begin{array}{l}\text { To determine the probability of failure or } \\
\text { reliability of components and systems }\end{array}$ \\
\hline Optimization & $\begin{array}{l}\text { To determine optimum design parameters that } \\
\text { meet some objectives, e.g. minimum cost, } \\
\text { weight, or POF }\end{array}$ \\
\hline
\end{tabular}

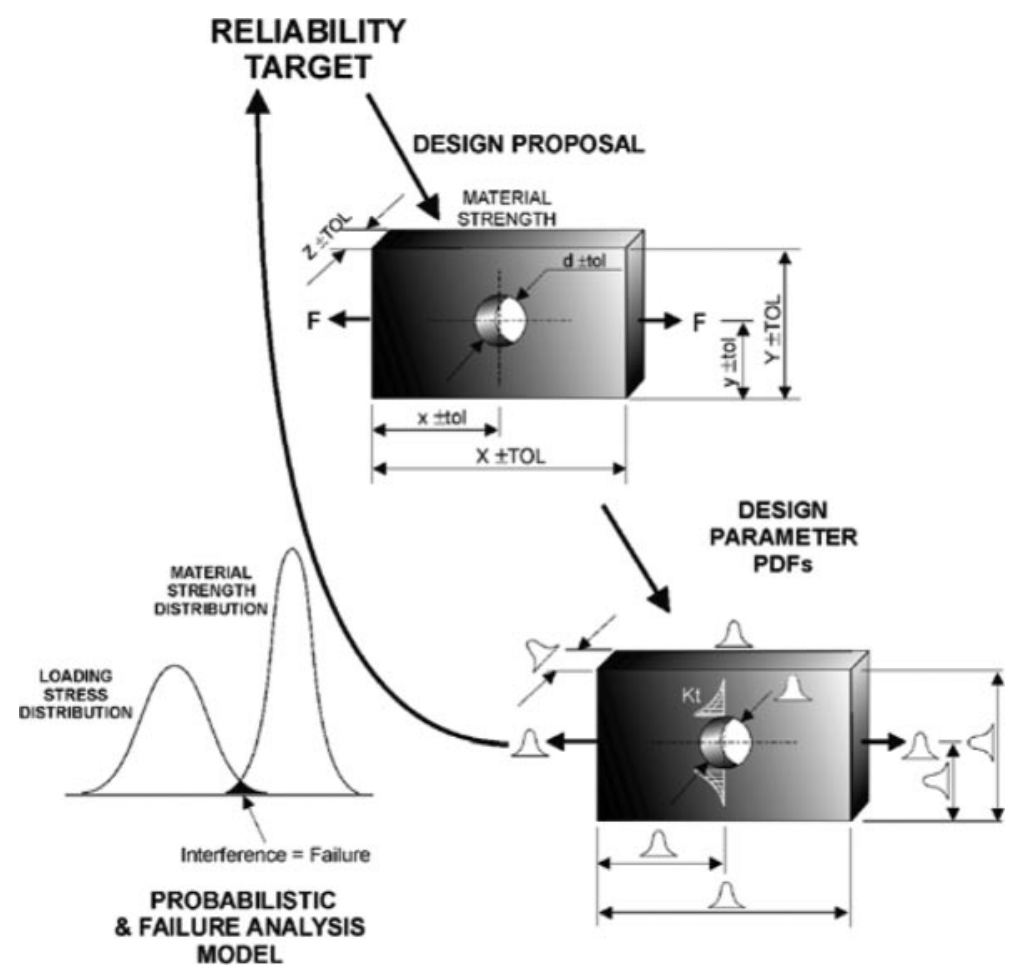

Fig. 1 Reliability prediction using stress-strength interference approach 
of the variability in design parameters is a large determinant of the reliability of a product in service and so its success in avoiding failure [13]. Therefore, all the design parameters, material properties, dimensions, and loads, are shown as statistical distributions to increase the variability understanding, rather than nominal, minimum, or maximum values, which is typical in deterministic design. The distributional nature of the stress and strength and the degrees of interference reflect the final POF prediction through an appropriate failure model and probabilistic method. Typically, a reliability target is converged upon through design analysis iteration.

The reliability prediction process using probabilistic methods for mechanical design involves the following key stages.

1. Identify the failure mode(s) for the product design.

2. Determine the performance function(s) that best describe the failure mode(s).

3. Statistically characterize the most important design parameters included in the transfer function(s) with the most appropriate distribution types.

4. Select the most appropriate probabilistic method and computational platform based on cost, time, accuracy, and robustness.

5. Compute the performance function as a random variable.

6. Statistically characterize the performance parameter with the most appropriate distribution.

7. Compare the performance distribution to a failure resistance distribution.

8. Compute POF and therefore reliability.

9. Compare to reliability target/range.

10. Review the design.

At present, only larger companies seem to be aware of the importance of probabilistic methods and although successful in specific applications, the impact of PD on industrial practice and a company's design processes is limited to date $[\mathbf{1 4}, \mathbf{1 5}]$. From a recent survey of the popularity of methods in the management of technical risk in the UK for example, probabilistic methods were found to be used routinely, always, or often, by only 18 per cent of companies, with 82 per cent never or only occasionally using them [16]. Industry often finds it difficult to justify the validity and accuracy of prediction from probabilistic methods, because it relies on detailed knowledge about design parameters and performance functions to enable plausible results to be produced. Design imprecision (e.g. lack of definition, alternatives) reduces as design matures after the concept design phase and well into the embodiment stage [17]. In the early design stages, imprecision is great (lack of definition, choice of alternatives) particularly limit the applicability of probabilistic designing. Therefore, the methods can only be

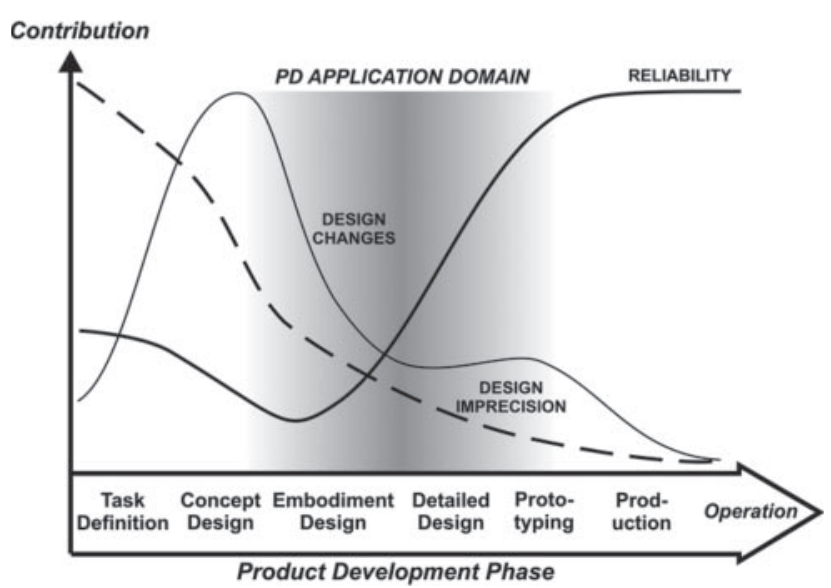

Fig. 2 General application domain of probabilistic design in product development, adapted from [18-20]

applied well into the embodiment phase as shown in Fig. 2 adapted from [18-20]. However, the potential benefits tend to be restricted and making any changes to the design will be costly at this later stage. Probabilistic methods are still useful in the early stages, particularly to help guide design decisions, and in later stages POF may be refined and confirmed by regulations, specifications, testing, etc.

Based on literature review and industrial experiences, the success of DFR using probabilistic methods is influenced by a number of critical factors $[15,21,22]$.

1. Effective data management: Lack of availability and/or poor documentation (context, uncertainty, error) of data describing design and performance parameters.

2. Verification and validation: The identification of critical failure mode(s) for the system and the development of mathematical model(s) of the physics of failure. Systematic procedures to establish confidence in analytical and simulation models.

3. Method selection strategy: Trade-off between computation time and cost of applying probabilistic methods to meet a required accuracy for resource efficiency. Particularly important in situations where the modelling is complex.

4. Designing to reliability targets: Comparing POF to reliability thresholds, considering severity of failure consequence.

5. Effective management of DFR process: The provision of approaches to facilitate all of the above issues e.g. record variable and model information, outcomes to support current and future design reuse is an important requirement, as probabilistic design analyses are more knowledge intensive compared to traditional 
philosophies in design e.g. deterministic or interval.

6. Education and awareness: Severe educational and cultural obstacles, comprising poor education in, knowledge of, and/or shear reluctance to apply statistics-based methods; the latter mainly caused by a dominance of deterministic design practiced in academia and industry.

The application of probabilistic methods for improving mechanical reliability requires significantly more effort and commitment to resources in order to gain maximum impact. As companies are relying more on computational methods in product development, uncertainty in all aspects of the process will influence the actual reliability obtained in service. Various probabilistic methods have been developed for characterizing uncertainties in engineering analysis, but mainly the approaches are deemed unrealistic or inapplicable to the general context of engineering design. In order to facilitate more effective use of the probabilistic methods, the above factors must be overcome. In this paper, a systematic framework for designing to reliability targets using probabilistic methods considering all aspects presented is outlined. A methodology for designing to reliability targets is discussed and a case study will demonstrate the utilization of the probabilistic methods developed through a proforma.

\section{EFFECTIVE DATA MANAGEMENT}

To be able to evaluate reliability using probabilistic methods, the designer needs much more information than for a deterministic evaluation [23]. Preferably, PDFs should be used to characterize the statistical data found from experiment for critical parameters. Software has been developed to support the initial stages of probabilistic calculations by automating this procedure and may be used to 'fit' sample data, either in discrete or histographic format, to a selection of important PDFs for engineering such as the normal, lognormal, extreme value (minimum and maximum), Weibull (two and three parameter) types. The PDFs listed provide all the properties needed to represent design parameter characteristics in reality, e.g. zero threshold or random values that are never below zero or skewed to the right or left. Typically though, only sufficient data is collected in order to determine the mean and standard deviation due to limited resources and time. Given such constraints, a lack of effective data management strategies means that confidence can not be established to perform a reliable probabilistic evaluation. Ideally, sample sizes in order to determine PDF parameters should be 30 or more, preferably 50 or 100 when dealing with histographic data. Small samples can yield important information about variability, but not necessarily define with confidence the shape of the PDF. The normal distribution is applicable is such situations, the mean and standard deviation being useful in the costeffective but low accuracy probabilistic methods such as first-order second moment (FOSM) and FORM.

Where PD has been applied in the past, it is usually quite late in the design process because design parameter information and knowledge of the service condition accumulates and matures at this stage (see Fig. 2). Probabilistic methods such as FOSM and FORM allow the designer to perform a sensitivity analysis of the design performance with respect to the design parameters to give an idea of their impact. With judicious selection of simplified performance models (e.g. closed-form equations) and cost-effective probabilistic methods populated with data from similar or past design cases, their application may be focused earlier in the design process to select initial design schemes i.e. concept selection, or to focus data collection on critical parameters. The identification of the critical parameters earlier in a design allows more efficiency, in terms of design cycle time, data collection, and increased flexibility in component testing regimes that may be transferable to other system models for variant design. At later design stages, more detailed models (e.g. FEA or MBS) applied with robust probabilistic methods could then be used to obtain more accurate predictions of failure probability or design performance.

It can be argued that probabilistic methods can be used only when all the needed statistical data is available [24]. The use of probabilistic methods for original or innovative design is, therefore, less suitable compared to adaptive or variant design $[\mathbf{2 5}, \mathbf{2 6}]$. This is due to the availability of similar design data typically in variant design cases. Effective data management strategies should deal with uncertainty, and support greater reuse of previously collected data in variant applications. Improved documentation of data that can be usefully reused in PD should describe uncertainty, applicability, and limitations of the data [27]. For example, providing the facility to describe uncertainty in company data management systems such as product data management and product lifecycle management systems could help encourage data sharing across functions such as design, manufacturing, and service, and leading industrial sectors and software vendors are developing frameworks and standards for product lifecycle support [28].

In addition, most conventional published sources only quote deterministic values such as minimum, nominal values, interval, etc. Publishing statistical information such as standard deviation, coefficient of 
variation, etc. for dimensions, material properties, and loading conditions will certainly encourage more PD applications by industry $[\mathbf{5}, \mathbf{2 9}]$. Component suppliers have a key role in this area, but are reluctant to release perceived 'sensitive' statistical data concerning properties and performance of components [30]. The implementation of six sigma in many companies is encouraging close collaboration with suppliers in assuring dimensional process capability and quality levels and the development of process capability databases. This philosophy should be extended to other design parameters useful to probabilistic designing, e.g. material properties databases; however, statistical data of mechanical properties is scarce [5].

\section{VERIFICATION AND VALIDATION}

The reliability prediction from probabilistic methods is usually sensitive to the accuracy of the physics-offailure models. In many mainstream engineering and particularly in early stages, accuracy in the models used does not fully justify resources for PD. The exception is in the aerospace and nuclear industries where many applications have been derived. With the move towards virtual product development, however, engineers need to deliver optimum products to customers, with specified target reliabilities, rapidly and cost-efficiently [31]. There is greater need to verify and validate performance predicted from simulation models to provide a basis for making design decisions. Verification and validation $(V \& V)$ efforts will facilitate greater use of probabilistic methods through better understanding of the model, its uncertainty and limitations. Verification is often defined as 'ensuring that the computer program of the computerized model and its implementation are correct' [32]. Verification is concerned with 'solving the equations right'. Validation is usually defined as substantiation that a computerized model within its domain of applicability possesses a satisfactory range of accuracy consistent with the intended application of the model [32].

Validation is concerned with 'solving the right equations'. Generally, verification involves code checking and visualization, whereas validation involves comparison with real data and other models [33].

Aspects of the V\&V of simulation models are depicted in Fig. 3.

Zio and Apostolakis [34] classified model uncertainty into conceptual model uncertainty, mathematical model uncertainty, and computer code uncertainty. Uncertainty in the conceptual model is caused by deficiencies in knowledge of the physical behaviour, e.g. stress analysis often requires simplifying assumptions. Nilsen and Aven [35]

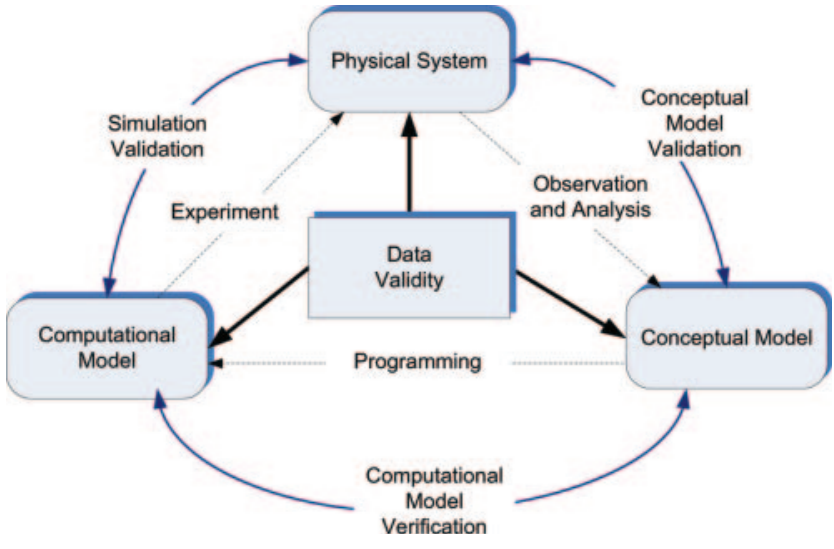

Fig. 3 V\&V of simulation models, adapted from [32]

further distinguished between model discrepancies as a result of the lack of knowledge and deliberate simplifications due to economy and convenience. Computational methods are concerned with the techniques and platforms for solving the performance functions. The platforms to perform analysis may be a closed-form calculation, numerical algorithm involving discretization such as finite differentiation and integration. In numerical methods such as FEA or CFD, mesh density is well known to affect the accuracy of results obtained [36].

Validation of reliability, or POF estimation, for mass-produced items is feasible, but often found to be prohibitively expensive as reliable products are expected to fail infrequently. Reliability prediction can be sensitive to errors in the models. For one-off high-reliability designs, there will be virtually no objective data to correlate the reliability estimates to. Still V\&V can be done meaningfully for the physics-of-failure models by systematically characterizing the model uncertainty, as these ultimately contribute to the errors in reliability prediction. In a $V \& V$ framework, modelling errors can be characterized by comparing the experimental and simulation results under a controlled experiment employing statistical techniques such as hypothesis and goodness-of-fit tests. Combined with probabilistic methods for characterizing uncertainty in design parameters, the confidence in reliability prediction can provide useful insight into potential errors associated with the estimates and how these might affect the resulting design decisions.

In this paper it is argued that companies should spend resources in a systematic $V \& V$ process to provide an indication of the relative levels of confidence for the range of models routinely applied. Such a process should characterize the range of validity, explicit assumptions and simplifications made, alternative and benchmark models, etc. For 
a variant and parametric design case, the exploration of the design space should be systematically correlated to evidence from test and in-service in order to populate error functions that can be used earlier in the design process to correct for uncertainty in the methods applied. It can be argued that in this way, understanding of epistemic uncertainty, i.e. the lack of knowledge (level of ignorance) about the physical system that is being modelled, in computational models can be accumulated and used to update the model for future applications [37].

\section{METHOD SELECTION STRATEGY}

There are many probabilistic methods available to the engineer; the choice is often based on familiarity or availability of commercial software in-house. However, engineers can make better informed selections if they understand the capabilities and limitations of all available methods, in a relative manner. The methods are grouped here according to their similarity, i.e. deterministic-based approaches (level I), approximation methods (level II), and exact methods (level III). These probabilistic methods themselves introduce varying levels of uncertainty to reliability prediction. The levels of uncertainty introduced depend on how the uncertainty in design parameters is characterized and how the performance functions are evaluated. Two types of approximation are typically performed to reduce the high number of iterations required in the exact methods (simulation techniques) in reliability problems. Table 2 consolidates and summarizes in terms of 'primers' to provide engineers with the basic

Table 2 Primers for reliability methods

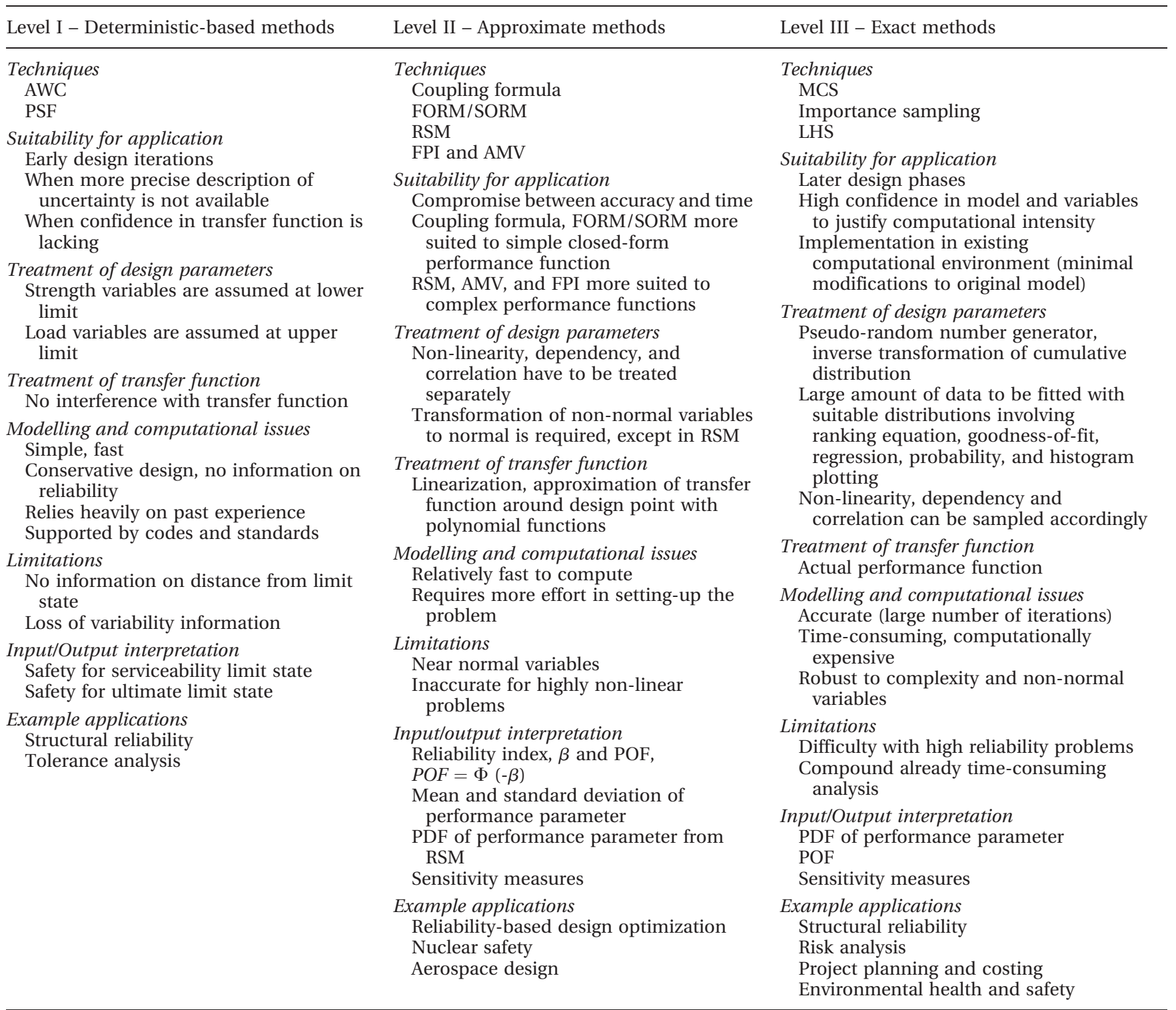


information and guidance for their application. Each primer, includes sections under suitability for application, treatment of design parameters and performance function, modelling and computational issues, limitations, input/output interpretation, and examples of typical applications. Absolute worst case (AWC) and partial safety factor (PSF) are deterministic approaches considered as level I methods. The level II methods include FOSM method, FORM, and the second-order reliability method (SORM), response surface methodology (RSM) and fast probability integration (FPI)/advanced mean value (AMV). The level III methods are simulation techniques such as MCS and Latin hypercube sampling (LHS). A mathematical treatment of all the methods listed is provided in reference [4].

Although useful in the initial education of the novice and further awareness for the experienced practitioner, this knowledge must be applied in a more strategic context to guide the selection of methods that are computationally efficient. The Society of Automotive Engineers $[\mathbf{1 5}, \mathbf{3 8}]$ provides several strategies for integrating probabilistic methods into the design process based on accuracy, and computation time. In order to guide method selection based on modelling and computational issues, four evaluation criteria are proposed, based on time, cost, accuracy, and robustness. The assessment of these criteria is demonstrated through a mechanical design case study, that concerns the failure of a bolted assembly through joint separation [4]. The performance function and data for this problem can be readily formulated and collated, and a POF prediction is sought using each method (with exception of level I methods where this is not possible).

The following criteria are used to compare the efficiency and effectiveness of each method in a relative manner.

1. Time required for probabilistic analysis compared with the conventional deterministic approach; a combination of set-up (analysis) time and computation time. The set-up time is a 'one-off' cost and includes time in learning the method and creating the model whereas computation time accounts for evaluating the model for probabilistic information. For probabilistic methods to have maximum acceptance by engineers, the time to perform an analysis must not be significantly more than that over the current time to perform deterministic design calculations [15], but it is inevitable that this will always be the case [39]. Justification also needs to be made for initially extending design phases in order to accommodate probabilistic method utilization.

2. Cost of implementing probabilistic methods in terms of the equipment and software required.
These are mainly commercial limitations and are dictated by the size of the company to how much they can invest in software and training if needed. Software may be commercially available or a commercial package that has the facility to integrate probabilistic algorithms and procedures. This is the initial cost incurred in acquiring and implementing the methods. Other costs involved in learning computer languages and model creation have been consolidated into the set-up time.

3. Accuracy of the probabilistic modelling results. The accuracy required from the use of the probabilistic method is dependent on the severity of failure consequences and the stage in the design process the method is utilized (this will be discussed in more detail later in terms of reliability prediction). The achievable accuracy for the different methods will be compared against a benchmark solution using MCS and $10^{6}$ iterations. The accuracy here does not include errors caused by the performance function (which has been discussed previously in section 3).

4. Robustness of the method towards the complexity of the performance function. It comprises the ability of probabilistic methods to cope with non-linearity in the performance functions, non-normal variable distributions, and the number of degrees of freedom in the performance functions.

Figure 4 shows all the relative ratings systems developed for the evaluation criteria. Accuracy here is defined as the error between the POF determined using each probabilistic method and that determined from benchmarked solution. Note that POF predictions for AWC and PSF are not available being deterministic approaches.

From the results of the analysis of a typical mechanical engineering design problem, a number of relationships can be drawn between the evaluation criteria to aid the identification of areas of favourable and unfavourable application of probabilistic methods. Figure 5 indicates an inverse relationship between accuracy and total time. At the extremes of this general trend, MCS requires long execution time for this number of iterations whereas FOSM and FORM are rapid, but are the least accurate. FOSM and FORM are more suitable in the initial stages where high accuracy is not needed, especially if there is limited data. MCS can be applied in later stages where accuracy becomes more important as the design proceeds and more complete data descriptions through PDFs is necessary to populate the simulation models. Methods such as RSM, AMV and FPI represent a trade-off between accuracy and time and are within 10 per cent of the benchmarked result in the bolted joint case. For problems with time 


\begin{tabular}{|c|c|c|c|}
\hline \multicolumn{2}{|c|}{ Set-up and Computation time scale } & \multicolumn{2}{|l|}{ Ratings } \\
\hline \multicolumn{2}{|c|}{ Very short } & \multicolumn{2}{|l|}{1} \\
\hline \multicolumn{2}{|c|}{ Short } & \multicolumn{2}{|l|}{2} \\
\hline \multicolumn{2}{|c|}{ Reasonable } & \multicolumn{2}{|l|}{3} \\
\hline \multicolumn{2}{|c|}{ Long } & \multicolumn{2}{|l|}{4} \\
\hline \multicolumn{2}{|c|}{ Very long } & \multicolumn{2}{|l|}{5} \\
\hline \multicolumn{2}{|c|}{ Cost scale } & \multicolumn{2}{|l|}{ Ratings } \\
\hline \multicolumn{2}{|c|}{ Simple Calculation } & \multicolumn{2}{|l|}{1} \\
\hline \multicolumn{2}{|c|}{ Calculator } & \multicolumn{2}{|l|}{2} \\
\hline \multicolumn{2}{|c|}{ Spreadsheet } & \multicolumn{2}{|l|}{3} \\
\hline \multicolumn{2}{|c|}{ High level language } & \multicolumn{2}{|l|}{4} \\
\hline \multicolumn{2}{|c|}{ Commercial package } & \multicolumn{2}{|l|}{5} \\
\hline \multicolumn{3}{|c|}{ Robustness towards complexity of performance function } & \multirow{2}{*}{ Ratings } \\
\hline Objective Function & Variables & Degree of Freedom (DOF) & \\
\hline Linear & Normal & Low & 1 \\
\hline Linear & Normal & High & \multirow{2}{*}{2} \\
\hline Linear & Non-normal & Low & \\
\hline Linear & Non-normal & High & \multirow{2}{*}{3} \\
\hline Non-linear & Normal & Low & \\
\hline Non-linear & Normal & High & \multirow{2}{*}{4} \\
\hline Non-linear & Non-normal & Low & \\
\hline Non-linear & Non-normal & High & 5 \\
\hline
\end{tabular}

Fig. 4 General ratings used for evaluation criteria

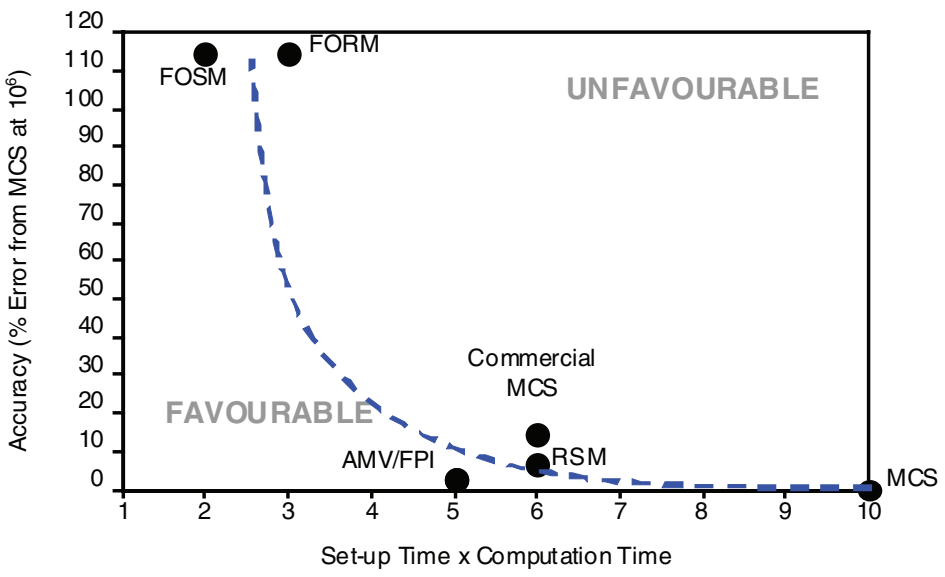

Fig. 5 Probabilistic methods comparison - accuracy versus total time

constraints and complex performance functions, these methods are preferred, but the more robust the method is, the more expensive it is as illustrated in Fig. 6. It is interesting to note that the deterministic methods (AWC and PSF) are very favourable in the comparative evaluation of robustness and cost. However, it is evident that they do not provide any variability information and, therefore, are outmoded as far as probabilistic design for mechanical reliability prediction is concerned. The probabilistic methods that are a good compromise for this case study are AMV/FPI.

Besides comparing probabilistic methods based on the modelling and computational attributes, method selection can also be assisted by: (a) the available data (precision) characterizing the design parameters;

(b) the accuracy of the performance function.

The selection of methods may be suited to precision levels in the data and the accuracy of the performance function as indicated in Figure 7 . When the accuracy in the performance functions is poor, the use of low-level probabilistic methods is advisable. However, if there is sufficient confidence in the performance function (through $\mathrm{V} \& \mathrm{~V}$ process), every effort should be made to improve the quality of data used in the analysis. When the precision in data is low, further testing may be conducted to further establish variability in design parameters before more advanced probabilistic methods are applied. 


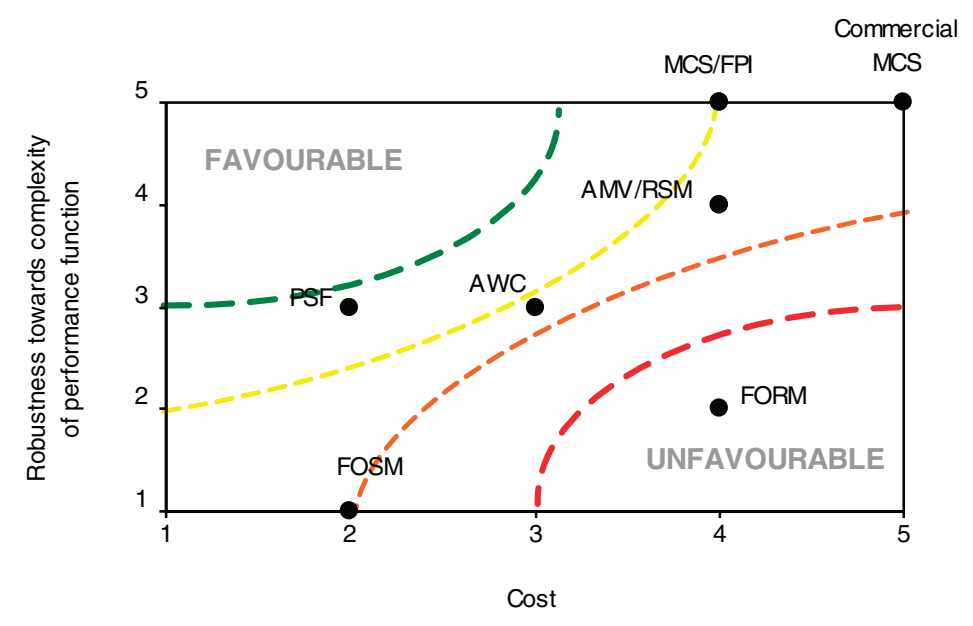

Fig. 6 Probabilistic methods comparison - robustness versus cost

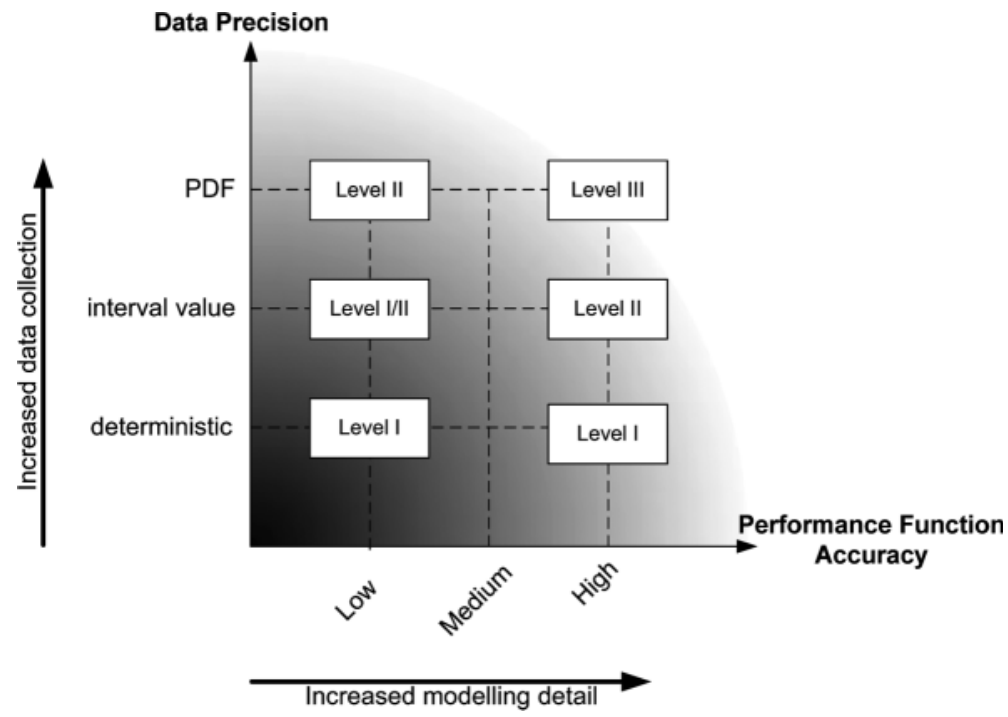

Fig. 7 Probabilistic methods and confidence in data and performance function

Sensitivity analysis from the low-level probabilistic methods could guide further data collection efforts or variability in critical variables could be controlled more effectively before high-level methods and complex computational models are employed. As the design progresses, the precision in data increases as more information is collected and therefore more advanced probabilistic methods also become more suitable. However, more accurate models need to be used to justify the effort in data collection and computational intensity of the more advanced methods.

\section{DESIGNING TO RELIABILITY TARGETS}

Reliability can be defined as the ability of a system or component to perform its required functions under stated conditions for a specified period of time.
Where reliability is actively considered in product design, it tends to be done relatively late in the product development process. DFR makes use of computational tools to model the physics of failure or failure mechanism allowing for earlier assessment of reliability in the design process. Designing to reliability targets involves the interpretation and consideration of the probability associated with satisfying the target performance requirements (or the thresholds of POF). Probabilistic methods are used in a stress-strength interference analysis to provide a mathematical and quantifiable estimate of the POF or reliability. Some industrial sectors may feel that allocating a reliability or a POF target to a product at the design stage may expose them to litigation in the event of possible safety critical failures later during the use of the product by the customer. Some may also not deem a reliability target relevant due to low volume of production. If a company 
makes just ten products a year, how can it make sense of a reliability target of 0.999 or a POF of 1 in 1000 ? Low volume does suggest high value and therefore performing PD could offset the high failure costs that can accrue and therefore does not lose its application relevance.

To be practical, a decision must be made as to the reliability target appropriate for the application [40]. What determines an acceptable value depends to a great extent on the following factors; safety and number of people affected by the potential failure mode(s), product complexity, duty cycle or product lifetime, and the costs of failure (warranty, product liability, insurance). A formal analysis is needed to aid decision-making in such complex situations. An appreciation of the severity of failure consequence together with POF or reliability would be useful because products need to be more reliable in safety critical cases. Research into the effects of non-conformance and associated costs of failure found that an area of acceptable design can be defined for a component characteristic on a graph of POF versus severity of consequence [5]. Here then are the two main elements of risk in the mechanical design context [41, 42]- Probability of failure, or how many times do we expect the failure to occur? - and severity, of what are the consequences on the customer or environment? In mechanical design, it is a good assumption that the product fails from its weakest link, and because 100 per cent of the failures by the nature of stress rupture are found in the field (corresponding to the useful life period of the 'bath tub' curve as oppose to early quality-related failures and late wear-out failures), the acceptable design is set at a failure cost equivalent to 1 per cent of total product cost. Design target reliabilities should therefore be set to achieve minimum failure cost $[\mathbf{2 6}, \mathbf{4 3}]$. From these arguments, acceptable thresholds set in a FMEA reliability (1-POF) or occurrence (parts per million, ppm) and severity (S) from 1 (little or no effect) to 10 (catastrophic consequence) can be drawn on a reliability target map as shown in Fig. 8.

The reliability target map includes areas associated with acceptable design, unacceptable, conservative, and overdesign. The overdesign area is probably not as important as the limiting POF for a particular severity rating, but does identify possible wasteful and costly designs. Various authors have presented target POFs ranging from $10^{-3}$ for unstressed applications to $10^{-9}$ for intrinsic reliability $[2,26,43]$, but with limited consideration of safety and/or failure cost. These values fit in well with the reliability map proposed, recognizing that as failures get more severe, they cost more, and so the objective must be to reduce the POF through the use of probabilistic methods, as the severity of consequence is very difficult to affect. A risk matrix (occurrence versus severity) is often adopted in industry to prioritize risk elements qualitatively into low, medium, and high categories [44]. On the other hand, probabilistic risk assessment requires full quantitative assessment of the occurrence and severity to derive the risk curves [45]. The integrated use of FMEA in the setting of reliability targets also ties in PD more with the traditional methods in the design process, especially as around 70 per cent of companies use FMEA in the UK to identify potential failure modes and prioritize risk [46].

In developing a reliable product, a number of design schemes should be generated to explore each for their ability to meet the target reliability. Evaluating and comparing alternative schemes and choosing the one with the highest predicted reliability, or lowest POF, will provide the most effective design solution ultimately and can reduce development times compared to designs that pass through many iterations, although the latter is generally more popular in industry [47]. This particular application mode of PD is more suited to the less computationally intense methods such as FOSM and FORM, but also means that reliance on high accuracy, absoluteness, and exactitude expected from PD is reduced. The approach has also been proposed by many other researchers in an attempt to align further probabilistic methods with current design methods [48-50]. It is important in early stages to bear in mind the reliability values are still subject to refinement, early awareness of how feasible the design solution is to satisfy a given reliability target will avoid later costly iteration (refer to Fig. 2).

Research has shown that even the most complete computer-supported methods do not enable the designer to predict reliability with sufficiently high statistical confidence and therefore absolute values may be unrealistic [23]. In DFR, it is often the case that one relies on a single measure or point value to make a judgement about the adequacy of a design. This practice neglects the effects of uncertainties in data, model, and the probabilistic methods in reliability prediction resulting in over- or under-designing of a system, which are both costly to the company. Particularly in cases where the failure consequences are high, targets should therefore be a central measure bounded by some range which spans a space of credibility, never a point value because of the underlying uncertainty in the design parameters and models used for reliability prediction [51]. In early design stages, iterations are inevitable, but systematic approaches can facilitate design decisions to converge the design towards targeted thresholds more rapidly. An approach for facilitating the application of PD is described next using a proforma. 


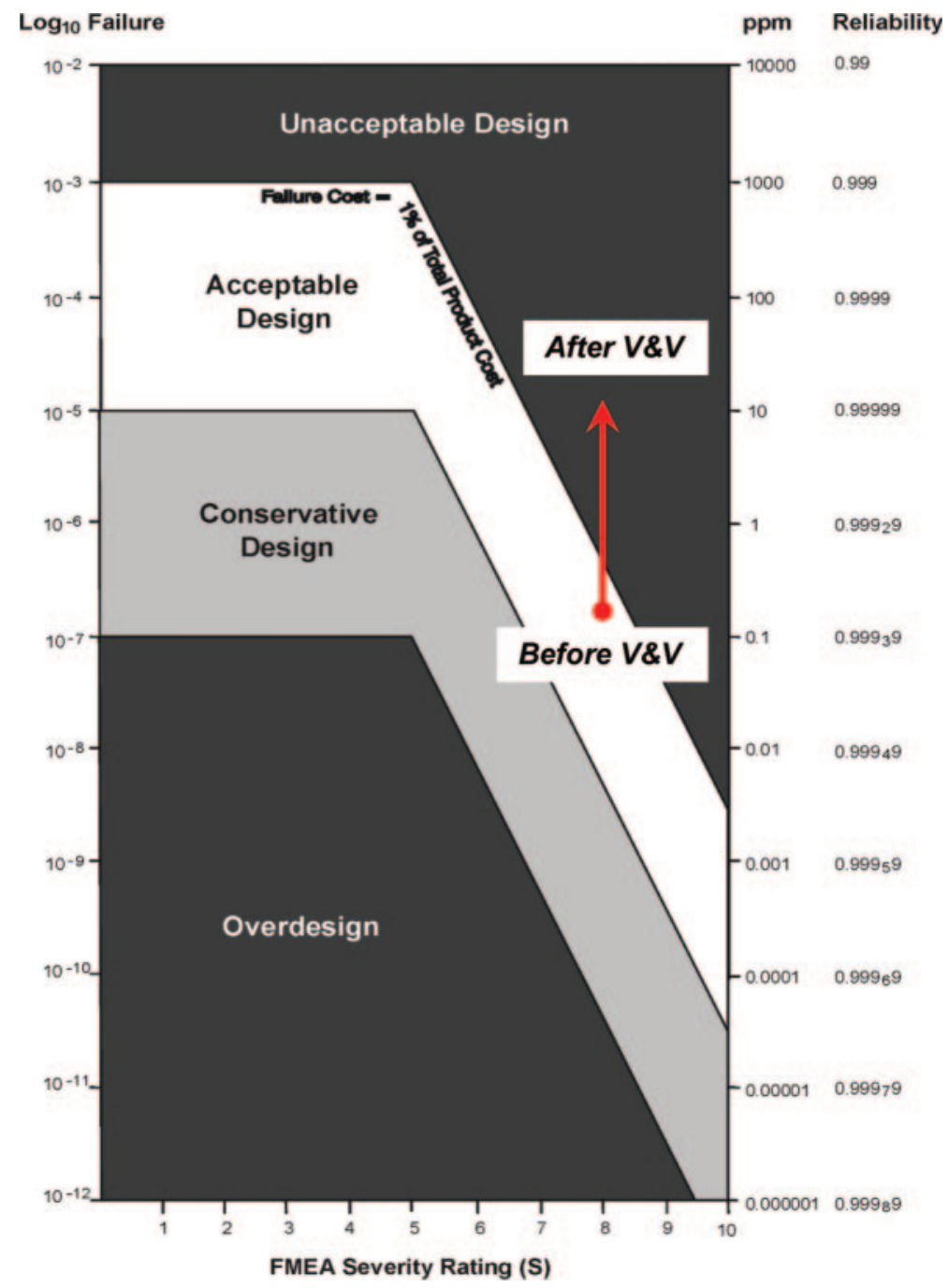

Fig. 8 Reliability target map based on FMEA severity (S)

\section{EFFECTIVE MANAGEMENT OF DFR PROCESS}

Several key steps in designing reliable products are summarized below, in order to encourage industrial uptake of probabilistic methods in DFR.

1. Identification of key design parameters and statistical data characterization.

2. Identification of failure mode(s) and the corresponding performance function(s).

3. $\mathrm{V} \& \mathrm{~V}$ of the model (considering the physics-offailure model, probabilistic method, and software implementation).

4. Evaluation of POF for the identified failure mode (s), and uncertainty in the POF estimator.

5. Assessment of design acceptability against reliability target taking into account of uncertainties in the POF.

To make the probabilistic reliability evaluation more accessible and to capture the description of the problem (and phases of reliability design), the process can be facilitated by a proforma. The proforma was originally designed for a workshop on probabilistic methods in an automotive company [12]. Such a structured method provides a thorough breakdown of the problem. Engineers are guided from the problem formulation to the consideration of uncertainty in the models and parameters, and finally how this might impact on the reliability prediction and target set. The proforma is a form-based template that requires information to be provided in each field. Omission of any aspects of the proforma means complete confidence in PD application cannot be guaranteed.

A case study on shrink-fit design is used to illustrate the framework discussed in this paper using the proforma (Fig. 9). The design parameters are characterized probabilistically from experimental data and the performance function derived analytically, as summarized in the proforma. The failure mode 


$\begin{aligned} & \text { CASE OVERVIEW } \\ & \text { (Describe the problem) }\end{aligned}$
$\begin{aligned} & \text { ANALYSIS OF } \\ & \text { PROCESS } \\ & \text { (Describe the analysis } \\ & \text { process, e.g. series of } \\ & \text { models, diagrams, notations, } \\ & \text { manufacturing process used) }\end{aligned}$

\begin{tabular}{|l|l|l|}
\hline KEY DESIGN & $\bullet$ Shaft diameter, $d_{S}$ & Young's Modulus, $E$ \\
$\begin{array}{l}\text { PARAMETERS } \\
\text { What are the design } \\
\text { parameters you consider will } \\
\text { affect performance?) }\end{array}$ & $\bullet$ Hub inner diameter, $d_{H}$ & $\bullet$ coefficient of friction, $f$ \\
\hline
\end{tabular}

\begin{tabular}{|l|l|}
\hline $\begin{array}{l}\text { DATA COLLECTION } \\
\text { (Is any statistical data } \\
\text { available for those } \\
\text { parameters?) }\end{array}$ & - 27 samples for shaft diameter, hub diameter, hub thickeness, contact length \\
\hline
\end{tabular}

\begin{tabular}{|c|c|}
\hline $\begin{array}{l}\text { DATA } \\
\text { CHARACTERISATION } \\
\text { (Are the parameters } \\
\text { nonlinear, dependent, or } \\
\text { correlated to other variables?) }\end{array}$ & $\begin{array}{l}\text { - Correlated variables: } \\
\text { shaft diameter and hub diameter due to selective assembly }\left(\gamma=d_{s}-d_{H}\right)\end{array}$ \\
\hline
\end{tabular}

\begin{tabular}{|l|ll|}
\hline $\begin{array}{l}\text { PERFORMANCE } \\
\text { PARAMETERS } \\
\begin{array}{l}\text { What are the analysis } \\
\text { objectives? }\end{array}\end{array}$ & $\bullet$ Contact pressure, $P$ \\
\hline
\end{tabular}

\begin{tabular}{|l|l|}
\hline $\begin{array}{l}\text { MODELS } \\
\text { (How are the transfer } \\
\text { functions of the model } \\
\text { described? e.g. closed } \\
\text { formulae, FE model etc) }\end{array}$ & $P=\frac{E \gamma}{2 d_{S}}\left[1-\left(\frac{d_{S}}{D_{H}}\right)^{2}\right]$ \\
& Holding torque capability: traditional design formula \\
& $T_{H}=\frac{\pi}{2} f P d_{S}^{2} L_{H}$ \\
\hline
\end{tabular}

\begin{tabular}{|c|c|}
\hline $\begin{array}{l}\text { VERIFICATION \& } \\
\text { VALIDATION } \\
\text { (Are there any V\&V } \\
\text { procedures in place?) }\end{array}$ & $\begin{array}{l}\text { - FEA } \\
\text { - Experimental measurements }\end{array}$ \\
\hline $\begin{array}{l}\text { ERROR } \\
\text { CHARACTERIZATION } \\
\text { (first moment, second } \\
\text { moment) }\end{array}$ & $\begin{array}{l}\text { - } \text { Bias error, } \varphi=0.48 \\
\text { - }\end{array}$ \\
\hline
\end{tabular}

\begin{tabular}{|c|c|}
\hline $\begin{array}{l}\text { MODEL COMPLEXITY } \\
\text { (Degree of freedom, analysis } \\
\text { time, implicity, empiricism) }\end{array}$ & - short analysis time, explicit analytical equation \\
\hline $\begin{array}{l}\text { SOFTWARE } \\
\text { (What is the software required } \\
\text { to solve the models now?) }\end{array}$ & $\begin{array}{l}\text { - FEA-ABAQUSV6.3 } \\
\text { - Analytical-Matlab }\end{array}$ \\
\hline $\begin{array}{l}\text { PROBABILISTIC } \\
\text { METHODS } \\
\text { (What probabilistic design } \\
\text { technique(s) is used?) }\end{array}$ & $\begin{array}{l}\text { - FEA - Latin Hypercube (100) } \\
\text { - Design formula-Mcs }(100,000)\end{array}$ \\
\hline
\end{tabular}

\begin{tabular}{|c|c|}
\hline $\begin{array}{l}\text { RELIABILITY TARGET } \\
\text { How does result compare } \\
\text { with reliability target? (e.g. } \\
\text { reliability, performance, } \\
\text { design target, failure mode } \\
\text { etc.) }\end{array}$ & $\begin{array}{l}\text { - POF }=0.161 \mathrm{ppm} \text { for torsional resistance (failure mode causing yield in material } \\
\text { due to torsional stress), } v_{p O F}=7.88 \\
\text { - Severity Rating (S) }=8 \text { (very high-loss of primary function) } \\
\text { - Acceptable design (POF }<0.3 \mathrm{ppm} \text { from reliability target map) }\end{array}$ \\
\hline $\begin{array}{l}\text { RISK } \\
\text { How might modelling error } \\
\text { affect the reliability estimate? }\end{array}$ & $\begin{array}{l}\text { - } P O F=15.2 \mathrm{ppm} \\
\text { - Risk of POF under-estimation - increased warranty costs } \\
\text { - unacceptable design (POF >0.3 ppm from reliability target map) }\end{array}$ \\
\hline
\end{tabular}

Fig. 9 Proforma for designing to probabilistic target reliability 
considered here is failure of material due to maximum torsional stress. Given a FMEA severity of $S=8$ corresponding to the loss of primary function to transmit load when it fails, the design is found to be acceptable at $P O F=0.161 \mathrm{ppm}$. In fact, considering errors found in the $V \& V$ process when compared with statistical experimental measurements, reported in [37], the POF was found to increase to $15.2 \mathrm{ppm}$ (Fig. 8). This uncertainty shifts the design into the unacceptable region corresponding to $S=8$. Subsequently, engineers can make more informed decisions by considering the resulting safety issues and loss of function associated with under-estimation of POF taking into account of such modelling uncertainties. Associated work is developing a computeraided process model approach for this [52]. When each information element can be computationally interpretable, the greater benefits for reuse can be achieved, for example, to systematically collect evidential feedback to validate the methods and information used during the design.

\section{EDUCATION AND AWARENESS}

A major hurdle in adopting PD in industry is the education of designers and engineers in probabilistic and statistical design methods [53]. As part of a recent study, an exam was undertaken by graduate engineers to test their understanding of probability theory [54]. The results indicated that graduates could remember only a few concepts from the probability theory they had been taught as undergraduates. Since, probability theory is taught as a single topic within an engineering mathematics unit early in degrees typically, this means that it has been largely forgotten by the time that students graduate. As a consequence graduates as well as more experienced engineers are equally reluctant in applying these methods $[\mathbf{5 4}, \mathbf{5 5}]$. Incorporating probability concepts into mainstream subjects such as solid mechanics, can enable students to develop confidence in probability theory and to develop an awareness of the presence and source of uncertainty in common engineering problems. Skills in organizing, modelling, and characterizing data will also be improved. Unfortunately in the UK, PD is not taught in many engineering degree courses. A final year module at the University of Bristol, includes probability theory and reliability prediction applications. It is hoped that graduate engineers that do undertake such studies leave academia with a probabilistic rather than deterministic mind-set, and challenge traditional design practice using the factor of safety approach in industry.

With the availability of commercial software, the learning time of probabilistic methods can be dras- tically reduced. Software that includes the wide range of probabilistic methods such as NESSUS [56] and NOESIS [57] help designers to model uncertainties in simulation and explore the design space. Other less comprehensive probabilistic commercial packages are also available, mostly to provide MCS on more user-friendly platforms. Probabilistic software when used is often developed in-house or, if commercially available, is of low flexibility, e.g. MCS or LHS add-ins to spreadsheets [16]. Reliable commercial computer software such as @Risk [58] and Crystal Ball [59] has nevertheless encouraged more applications of PD. However, MCS requires a high number of iterations $\left(10^{5}-10^{7}\right)$ to produce reasonably accurate results, as already mentioned. There have been many methods proposed in the literature to improve the efficiency of MCS using variance reduction techniques. LHS is a stratified without replacement method and results in more even sampling throughout the sampling regions by dividing it into strata of equal probability. Each stratum is sampled only once, reducing the number of iterations to the number of strata specified by the user. There are similar modifications to reduce the computation time and increase in efficiency of other probabilistic methods, for example, RSM, an approximate method [39].

Although it can be argued that computational time is redundant given the increase in the speed of computers recently, it is of major concern when PD is applied in applications such as FEA and MBS, where many thousands of calculations may be involved, amplifying simulation time. This is because design performance functions are implicit of the actual design parameters and uncertain system parameters are evaluated in a numerical manner. Numerically efficient probabilistic algorithms for evaluating this type of system response are therefore required [60]. The probabilistic utilization of these systems means either providing the user with the possibility with writing their own algorithms or interfacing with 'built-in' modules to facilitate probabilistic calculations. Several software packages have recently incorporated these capabilities. ANSYS Finite Element software has had a probabilistic module as an integral part of the package since version 5.7. In the current version of MSC.ADAMS for MBS analysis, probabilistic capabilities also include LHS.

\section{CONCLUDING REMARKS}

In the search for competitive advantage, manufacturing companies should look to new ways of designing products in order to accelerate lead times, reduce failure costs, and improve quality and reliability. During the last decade, a number of issues are 
both pushing the agenda for the application of probabilistic methods and also increasing their technical feasibility.

1. More powerful and reliable computational platforms developed for designers to conduct more complex calculations.

2. The increasing utilization of computer databases to store data on material properties, loads, and process capability values for dimensional characteristics, the latter mainly due the adoption of six sigma.

3. The need for more efficient, higher-performance products. The deterministic approach is not suitable for today's products where superior functionality and reliability should be designed-in.

4. Pressure to move to simulation-based design rather than expensive and time-consuming prototype testing to verify product performance.

The last point is particularly challenging. During the design of many products, the variability inherent in service loads, material properties and geometry parameters, and uncertainty in the simulation models is not well understood leading to uncertainty in design performance. As the traditional deterministic design approach fails to enumerate the situation as far as uncertainty is concerned, a series of prototypes are typically developed in order to discover and eliminate sources of failure due to these uncertainties, which is an expensive and time-consuming undertaking. For example, in the automotive industry it has been estimated that 40 per cent of the cost of product validation is due to the creation of prototypes [61]. Many manufacturing companies are looking to drastically reduce the number of prototypes developed at various stages of the product development process in an attempt to reduce costs, moving to a simulation-based design process rather than one that primarily relies on prototype testing. There is a need for industry to more rigorously and systematically consider uncertainty, characterize relationships and record correlations between experimental observations, identify critical components and model predictions in order to improve confidence in results. Incorporating variability in the computational models allows the effect of uncertainty on design performance to be fully investigated. The probabilistic approach is the only wellestablished method that can achieve this $[\mathbf{2 9}, \mathbf{6 2}, \mathbf{6 3}]$. In practice, PD will never completely replace prototype testing - at least one being needed for final design verification [23]. For example, in the automotive sector, prototypes and vehicle proving grounds will continue to be necessary for full vehicle sign off [64] and can actually contribute to the data needed for PD. However, the use of probabilistic methods at various stages in the design process with
V\&V can considerably reduce the need for intermediate prototypes by the strategic integration of component testing and designing to reliability targets leading to design solutions much closer to the desired end result [26].

Although probabilistic methods have been adopted in some companies, and have been successfully applied to specific cases, a cultural and educational step-change is necessary for probabilistic methods to be integrated in mainstream engineering leading to a probabilistic 'mind-set' adopted by designers and engineers. A lack of awareness of their existence or usefulness, computational intensity, requirement for strong statistical knowledge, and difficulty and cost of data collection, are a few of the obstacles that limit their use to date. Little is required from the developers and researchers of PD in terms of maturity of the methods, but a key problem has been in consolidating the knowledge about these methods for advancing utility by industry. The focus should now be on the routine use of PD by companies in their design processes. With the information on method capabilities, application modes, and demonstrative case studies provided, optimized selection of probabilistic methods to suit specific new applications could be facilitated. Despite this, effective data management and $\mathrm{V} \& \mathrm{~V}$ efforts are all critical to the success of implementation and continued utility of probabilistic methods in designing for mechanical reliability.

\section{ACKNOWLEDGEMENTS}

The authors gratefully acknowledge the funding provided by the Engineering and Physical Science Research Council (EPSRC) for the Through-life Knowledge and Information Management Project (http://www-edc.eng.cam.ac.uk/kim/) under grant $\mathrm{EP} / \mathrm{C} 534220 / 1$ and the IdMRC under grant GR/ R67507/01 for the research reported in this paper.

(c) Authors 2009

\section{REFERENCES}

1 Crowe D. and Feinberg, A. (Eds) Design for reliability, 2001 (CRC Press, Lowell, Massachusetts).

2 Smith, D. J. Reliability, Maintainability and risk: practical methods for engineers; fourth edition, 1993 (Butterworth-Heinemann, Oxford, UK).

3 Riha, D. S., Thacker, B. H., Enright, M. P., Huyse, L., and Fitch, S. H. K. Recent advances of the NESSUS probabilistic analysis software for engineering applications. In Proceedings of the 43rd AIAA/ASME/ASCE/ 
AHS/ASC Structures, Structural Dynamics, and Materials (SDM) Conference, Denver, Colorado, 22-25 April 2002, paper no. AIAA-2002-1268 (AIAA, Denver, Colorado).

4 Goh, Y. M., Booker, J. D., and McMahon, C. A. A comparison of methods in probabilistic design based on computational and modelling issues. In Proceedings of 5th International Conference on Integrated Design and Manufacturing in Mechanical Engineering (IDMME'04), Bath, UK, 5-7 April 2004, paper no. 155 KluwerAcademic Publishers, Bath UK.

5 Booker, J. D., Raines, M., and Swift, K. G. Designing Capable and Reliable Products, 2001 (ButterworthHeinemann, Oxford, UK).

6 Mavris, D. N., Macsotai, N. I., and Roth, B. A. A probabilistic design methodology for commercial aircraft engine cycle selection. In Proceedings of the 1998 World aviation congress and exposition, Anaheim, California, 28-30 September 1998, paper no. SAE-985510 (SAE, California, USA).

7 Riha, R. J., Thacker, B. H., Hall, D. A., Auel, T. R., and Pritchard, S. D. Capabilities and applications of probabilistic methods in finite element analysis. The Fifth ISSAT International Conference on Reliability and Quality in Design, Las Vegas, Nevada, 11-13 August 1999.

8 Thacker, B. H., Rodriguez, E. A., Pepin, J. E., and Riha, D. S. Application of probabilistic methods to weapon reliability assessment. In Proceedings of the 42nd AIAA/ASME/ASCE/AHS/ASC Structures, Structural Dynamics, and Materials (SDM) Conference, Seattle, Washington, 16-19 April 2001, paper no. AIAA 2001-1458 (AIAA, Washington, USA).

9 Ayyub, B. M. and De Souza, G. F. M. Reliability-based methodology for life prediction of ship structures. Ship Structure Symposium, Arlington, Virginia, 13-14 June 2000.

10 Faragher, J. The implementation of probabilistic methods for uncertainty analysis in computational fluid dynamics simulations of fluid flow and heat transfer in a gas turbine engine. Report DSTO-TR-1830, Air Vehicles Division, Defence Science and Technology Organisation, Australia, 2006.

11 Schenk, C. A. and Schuëller, G. I. Buckling analysis of cylindrical shells with random geometric imperfections. Int. J. Non-Linear Mech., 2003, 38, 1119-1132.

12 Goh, Y. M., Booker, J. D., and McMahon, C. A. Uncertainty modelling of a suspension unit. Proc. IMechE, Part D: J. Automobile Engineering, 2005, 219(6), 755-771. DOI: 10.1243/095440705X28321.

13 Dasgupta, A. and Pecht, M. Material failure mechanisms and damage models. IEEE Trans. Reliab., 1991, 40(5), 531-536.

14 Howell, D. Industry fails statistical analysis. Prof. Engng, 1999, 12(1), 20-21.

15 Society of Automotive Engineers. Integration of probabilistic methods into the design process, Report No. AIR5080, Society of Automotive Engineers, Pennsylvania, USA, 1997.

16 Crossland, R., McMahon, C. A., and Sims-Williams, J. Survey of current UK practice in managing technical design risk. In Proceedings of International Conference on Engineering Design ICED '01, Glasgow, 21-23 August
2001 (Professional Engineering Publishing, Bury St Edmunds and London).

17 Moens, D. and Vandepitte, D. Non-probabilistic approaches for non-deterministic dynamic FE analysis of imprecisely defined structures. In Proceedings of the International Conference on Noise and vibration engineering (ISMA), Leuven, Belgium, 20-22 September 2004 (K U Leuven, Leuven, Belgium).

18 Bedford, T., Quigley, J., and Walls, L. Expert elicitation for reliable system design. Stat. Sci., 2006, 21 (4), 428-450.

19 Lemon, J. Why simulation should drive product development, 2007, available from http://www.iti-oh. com/Education/Articles/SimLedDev.htm, (access date 8 February 2008).

20 Giachetti, R. E., Young, R. E., Roggatz, A., Eversheim, W., and Perrone, G. A methodology for the reduction of imprecision in the engineering process. Eur. J. Oper. Res., 1997, 100(2), 277-292.

21 Hanson, K. M. A framework for assessing uncertainties in simulation predictions. Physica D: Nonline. Phenom., 1999, 133(1-4), 179-188.

22 Zhu, T. L. A reliability based safety factor for aircraft composite structures. Comput. Struct., 1993, 48(4), 745-748.

23 Fajdiga, M., Jurejevcic, T., and Kernc, J. Reliability prediction in early phases of product design. J. Engng. Desi., 1996, 7(2), 107-128.

24 Shigley, J. E. and Mischke, C. R. Mechanical Engineering Design, fifth edition, 1989 (McGraw-Hill, New York).

25 Andersson, P. A. Process approach to robust design in early engineering design phases. $\mathrm{PhD}$ Thesis, Department of Machine Design, Lund Institute of Technology, 1996.

26 Carter, A. D. S. Mechanical reliability and design, 1997 (Macmillan, London).

27 BOMEL Ltd. Probabilistic methods: uses and abuses in structural integrity, Health and Safety Executive contract research report, 398/2001, 2001.

28 International Organisation for Standardization. Industrial automation systems and integration - product data representation and exchange - Part 239: application protocol: product life cycle support, 2005.

29 Haugen, E. B. Probabilistic mechanical design. 1980 (Wiley-Interscience, New York).

30 Tata, M. and Thornton, A. Process capability database usage in industry: myth vs. reality. In proceedings of ASME Design Engineering Technical Conferences (DETC'99), Las Vegas, Nevada, 12-15 September 1999 paper number DEC99/DFM-8968 (ASME).

31 Shephard, M. S., Beall, M. W., O'Bara, R. M., and Webster, R. E. Toward simulation-based design. Finite Eleme. Anal. Des., 2004, 40, 1575-1598.

32 Sargent, R. G. Verification and validation of simulation models. In Proceedings of the 30th Winter simulation conference, Washington, District of Columbia, 13-16 December 1998, pp. 121-130, (IEE Computer Society Press).

33 Robinson, S. Simulation model verification and validation: increasing the users' confidence. In Proceedings of the 1997 winter simulation conference, Atlanta, Georgia, 7-10 December 1997, pp. 53-59 (IEEE Computer Society Press). 
34 Zio, E. and Apostolakis, G. E. Two methods for the structured assessment of model uncertainty by experts in performance assessments of radioactive waste repositories. Reliab. Engng Syst. Saf., 1996, 54, 225-241.

35 Nilsen, T. and Aven, T. Models and model uncertainty in the context of risk analysis. Reliab. Engng Syst. Saf., 2003, 79, 309-317.

36 Rieg, F. and Koch, F. Selection of finite elements considering loadcases and geometry. In Proceedings of International Conference on Engineering Design (ICED'01), Glasgow, UK, 21-23 August, 2001 (Professional Engineering Publishing, Bury St Edmunds and London).

37 Goh, Y. M., McMahon, C. A., and Booker, J. D. Improving confidence in simulation-based design through error functions. In Proceedings of ASME 2007 International Design Engineering Technical Conferences and Computers and Information in Engineering Conference (ASME IDETC/CIE 2007), Las Vegas, Nevada, 4-7 September, 2007, paper number DETC2007-34435 (ASME).

38 Long, M. W. and Narciso, J. D. Probabilistic design methodology for composite aircraft structures, US Department of Transportation report DOT/FAA/AR-99/ 2, and the Federal Aviation Administration Springfield, Virginia, 1999.

39 Craney, T. Probabilistic engineering design. reliability review. $R$ and $M$ Engng J., 2003, 23(2), 5-8.

40 Ditlevsen, 0 . Structural reliability codes for probabilistic design. Struct. Saf., 1997, 19(3), 253-270.

41 Haimes, Y. Y. Risk analysis of fracture and failure. Mater. Res. Innov., 1998, 2, 16-21.

42 Lough, K. G., Stone, R., and Tumer, Y. The risk in early design method. J. Engng Des., 2009, 20(2), 155-173.

43 Dieter, G. E. Engineering design: a materials and processing approach, third edition, 2000 (McGraw-Hill, New York).

44 NASA. Risk management procedures and guidelines. Report NPG 8000.4, 2002.

45 NASA. Probabilistic risk assessment procedures guide for NASA managers and practitioners, Version 1.1, 2002.

46 Arajou, C. S., Benedetto-Neto, H., Campello, A. C., Segre, F. M., and Wright, I. C. The utilisation of product development methods: a survey of UK industry. J. Engng Des., 1996, 7(3), 265-278.

47 Darlington, J. and Booker, J. D. Designing for fatigue resistance: survey of UK industry and future research agenda. In Proceedings of IDMME'04, Bath, UK, 5-7 April, 2004, paper no. 121.

48 Bieda, J. and Holbrook, M. Reliability prediction, the right way. Reliab. Rev., 1991, 11, 8, paper 25584-002.

49 Burns, R. J. Reliability: is it worth the effort? - an assessment of the value of reliability tasks and techniques. Microelectron. Reliab., 1994, 34(11), 1795-1805.

50 Klit, P., Jensen, F., and Ellevang, P. Reliable design methodology - the use and misuse of reliability data in the design process. In Proceedings of International
Conference on Engineering Design (ICED '93), The Hague, 17-19 August, 1993, pp. 1156-1164 (Professional Engineering Publishing, Bury St Edmunds and London).

51 Fragola, J. R. Reliability and risk analysis data base development: an historical perspective. Reliab. Engng Sys. Saf., 1996, 51(2), 125-136.

52 Giess, M., Goh, Y. M., Ding, L., and McMahon, C. A. Improved product, process and rationale representation and information organisation to support design learning. In Proceedings of International Conference on Engineering Design (ICED'07), Paris, France, 28-31 August, 2007.

53 De Weck, O., Eckert, C. M., and Clarkson, P. J. A classification of uncertainty for early product and system design. In Proceedings of ICED'07, Paris, France, 28-31 August, 2007.

54 Burgess, S. C., Booker, J. D., Barr, G., and Alemzadeh, K. An investigation into engineering graduates' understanding of probability theory. Int. J. Engng Educ., 2005, $21(3), 512-524$.

55 Amster, S. J. and Hooper, J. H. Statistical methods for reliability improvement. AT\&T Tech. J., 1986, 65(2), 69-76.

56 Southwest Research Institute. NESSUS overview, version 8.4, available from http://www.nessus.swri.org/, (accessed 26 June 2009). Institute.

57 Noesis Solutions. Noesis Optimus, version 5.3, available http://www.noesissolutions.com/, (accessed 26 June 2009).

58 Palisade Corporation. @Risk for Excel, version 5.0, available from http://www.palisade.com, (accessed 26 June 2009).

59 Oracle's. Crystal Ball, version 7, available from http:// www.oricle.com/crystalball/index.html (accessed 26 June 2009).

60 Jensen, H. A. and Sepulveda, A. E. Optimal design of uncertain systems under stochastic excitation. AIAA J., 2000, 38(11), 2133-2141.

61 Honeywell, T. Drive to cut prototyping. Prof. Engng, 2001, 14(23), 46.

62 Newell, J. F. and Rajagopal, K. R. Probabilistic methodology - a design tool for the future. Threshold Rocketdyne's Engng Journal for Power Technol., Fall 1989, http://www.pwrengineering.com/articles/probabalistic. htm.

63 Wojtkiewicz, S. F., Eldred, M. S., Field, J. R., Urbina, A., and Red-Horse, J. R. A toolkit for uncertainty quantification in large computational engineering models. In Proceedings of the 42nd AIAA/ASME/ASCE/AHS/ASC Structures, Structural Dynamics, and Materials (SDM) Conference, Seattle, Washington, 16-19 April, 2001, paper no. AIAA-2001-1455 (AIAA).

64 Plaskitt, R. J. and Musiol, C. J. Developing a durable product. In Proceedings of the Agricultural equipment technology Conference, Kansas City, Kansas, 20-23 February 2002, pp. 1-24 (American Society of Agricultural Engineers, Michigan, USA). 